\title{
Research and Application of New Polybasic Acid
}

\author{
Ning Mengmeng ${ }^{1, *}$, Wang Peng ${ }^{1}$, Chen Jinfeng ${ }^{2}$, Xu Zhengdong ${ }^{1}$, Long Changjun ${ }^{1}$, Li Yutao ${ }^{1}$, Kong Weizhong ${ }^{1}$, Jia \\ Jiangfen $^{1}$, Zeng Zhiguo ${ }^{1}$, Jia Yuanzhao ${ }^{1}$ \\ ${ }^{1}$ Engineering Technology Research Institute of Huabei Oilfield Co. \\ ${ }^{2}$ No.4 oil production plant of Huabei Oilfield
}

\begin{abstract}
Sandstone reservoirs in Huabei Oilfield are characterized by low porosity, low permeability, high clay content, strong heterogeneity and high reservoir temperature. In order to solve the problems of rapid reaction, short effective penetration distance and secondary precipitation in conventional acid system, a new composite acid system is studied. The experimental results show that the acid-rock reaction speed of the new composite acid system is lower than that of the conventional acid system; the chelating ability of $\mathrm{Ca} 2+, \mathrm{Fe} 3+$ and $\mathrm{Mg} 2+$ ions is stronger; the corrosion rate of $\mathrm{N} 80$ steel is $1.57 \mathrm{~g} / \mathrm{m} 2 \cdot \mathrm{h}$, far below the industry standard $(10-20 \mathrm{~g} / \mathrm{m} 2 \cdot \mathrm{h})$; the permeability of the core after acidizing increased by 3.5 times. This new type of composite acid system with slow reaction speed, scale inhibition and deep penetration is of great significance for acidizing low porosity and low permeability sandstone reservoirs in Huabei Oilfield.
\end{abstract}

\section{Introduction}

The reserves abundance in Huabei Oilfield is low, some sandstone reservoirs are characterized by low porosity and low permeability, high reservoir temperature and high clay mineral content, which make it more difficult to further improve oil recovery. Acidizing technology can effectively dissolve stemming and clay, expand pore throats, and improve the development of low-permeability oil and gas fields ${ }^{[1]}$.

At present, the concentration of iron ion is high in flow back fluid using the common acid system, which shows that the corrosion of the acid liquid to the downhole string is too high, and it needs to study a new appropriate acid system based on the actual feature of the oil field. For sandstone reservoirs, the conventional sandstone acid system has a fast reaction speed of acid-rock, serious sand production, easy to generate secondary and tertiary precipitation, short effective penetration distance of acidizing ${ }^{[2-3]}$.

For the acidizing of sandstone reservoirs, many scholars have proposed different types of low-damage acidizing fluids. The main goal of the acidizing is to achieve the goal of slow reaction and scale inhibition on the basis of maintaining dissolution ${ }^{[4-7]}$. At present, the chelating acid system with low damage and deep penetration has been studied and applied at home and abroad due to its excellent performance. The acid is mainly composed of hydrochloric acid, fluorine-containing salt and chelating agent. The fluoride salt can slowly release $\mathrm{F}^{-}$and slow down the reaction rate of acid-rock. The chelating agent has high chelating ability for metal ions such as calcium, iron and magnesium. It can effectively inhibit secondary precipitation; at the same time, the permeability of reservoir is improved ${ }^{[8-9]}$. The advantages of composite acid in the matrix acidizing of sandstone, its performance evaluation and field application have been widely concerned by many scholars ${ }^{[10-12]}$.

Based on the analysis of reservoir lithology and mineral composition in Huabei Oilfield, a new composite acid system suitable for Huabei Oilfield is proposed. The molecular structure, retardation, corrosion inhibition and chelating ability and application were comprehensively evaluated.

\section{Study on Molecular Structure of Composite Acid Main Agent (AH)}

The performance of the composite acid system is closely related to its own molecular structure. The hydrogen spectrum and carbon spectrum of the $\mathrm{AH}$ molecular structure were determined by NMR. The mechanism of measuring the molecular structure by NMR: under the irradiation of electromagnetic waves, the frequencies of carbon atoms and hydrogen atioms are different due to resonance absorption. The relative positions of different atoms are different on wave spectrum. NMR can provide atomic composition and molecular structure in complex systems under three-phase conditions, and is widely used in analytical chemistry and drug research ${ }^{[13-15]}$.

The results of HNMR showed that there were multiple $\mathrm{H}+\mathrm{s}$ in $\mathrm{AH}$. The test process was saturated with heavy water, and the hydrogen ion at the carboxyl group was replaced. In addition to the hydrogen ion at the carboxyl group, there were obviously three types, which appeared at $3.08 \mathrm{ppm}, 2.06 \mathrm{ppm}$, and $1.7 \mathrm{ppm}$, respectively. Among 
them, two types of similar $\mathrm{H}+$ overlap phenomenon were found at $3.08 \mathrm{ppm}$, which generally contains at least four types of hydrogen ions, and the ratio of the three major types of $\mathrm{H}+$ numbers is $6: 3: 2$.

The results of CNMR showed that $\mathrm{AH}$ contains 7 types of carbon, which are distributed at $68.33 \mathrm{ppm}, 56.57$ ppm, 26.56 ppm, etc., which contain multiple carboxyl groups (at 180 182 ppm).

The analysis of the molecular structure of the main agent $\mathrm{AH}$ indicates that the molecule belongs to the aminocarboxylic acid chelate compound. When the hydrogen ion is ionized, $\mathrm{AH}$ maintains a lower $\mathrm{pH}$, achieving better retardation; forming a plurality of ligands with the metal ions to exert chelation.

\section{Composite Acid AH Concentration Optimization}

Different concentrations of $\mathrm{AH}$ were used to test the acidity characteristics. The concentration is $6 \%, 8 \%, 10 \%$, and $12 \%$. Compare with $8 \%$ hydrochloric acid. When the $\mathrm{pH}$ of hydrochloric acid residual acid was 3 , the consumption of alkali liquor was taken as reference. From Fig. 1, it show that $10 \%$ of $\mathrm{AH}$ is similar to $8 \% \mathrm{HCl}$. Through experiments, it is found that the optimized acid concentration sample acid is $10 \%$, and the main acid formula of $\mathrm{AH}$ is $10 \% \mathrm{AH}+3 \% \mathrm{HF}$.

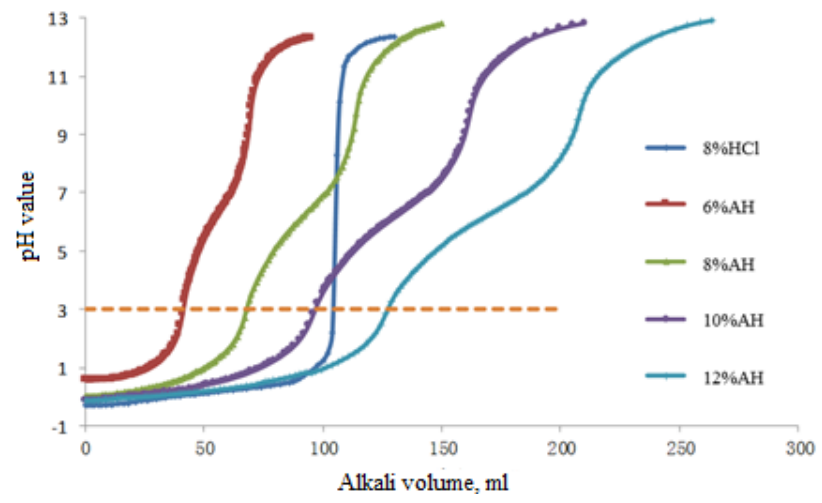

Fig. 1. Different concentrations of AH and hydrochloric acid acidity characteristic curve.

\section{Additive optimization}

\subsection{Corrosion Inhibitor}

Under the temperature of $120^{\circ} \mathrm{C}$, the corrosion rate of the composite acid on the N80 steel was tested by adding different corrosion inhibitors at $1 \%$ concentration $^{[13]}$. In Table 1 results show that the acid solution added to HSJ-A and HSJ-B has a higher corrosion rate on the N80 steel, far exceeding the industry evaluation criterion of the corrosion inhibitor; and with the HSJ-C the corrosion rate is only $1.57 \mathrm{~g} /\left(\mathrm{m}^{2} \cdot \mathrm{h}\right)$, which is far less than the standard value of the first-grade of corrosion inhibitor evaluation $\left[10-20 \mathrm{~g} /\left(\mathrm{m}^{2} \cdot \mathrm{h}\right)\right]$. Therefore, HSJ-C is preferred as a corrosion inhibitor.
Table 1. Corrosion inhibition performance of N80 at different corrosion inhibitors

\begin{tabular}{|c|c|c|c|}
\hline $\begin{array}{l}\text { Corrosion } \\
\text { inhibitor }\end{array}$ & $\begin{array}{l}\text { Corrosion } \\
\text { rate } \\
\mathrm{g} /\left(\mathrm{m}^{2} \cdot \mathrm{h}\right)\end{array}$ & Corrosion phenomenon & Conclusion \\
\hline HSJ-A & 45 & $\begin{array}{l}\text { The steel sheet is severely } \\
\text { corroded and the surface is black. }\end{array}$ & $\mathrm{Bad}$ \\
\hline HSJ-B & 23 & $\begin{array}{l}\text { The steel sheet is severely } \\
\text { corroded and the surface is black. }\end{array}$ & $\mathrm{Bad}$ \\
\hline HSJ-C & 1.57 & Smooth steel sheet & Good \\
\hline
\end{tabular}

\subsection{Cleanup Additive}

The surface tension tests were performed on different types and concentrations of surfactant. It can be seen from Fig. 2 that under the same concentration ZPJ-A has a relatively low surface tension compared with ZPJ-B and ZPJ-C. The surface tension of $2 \% \mathrm{ZPJ}-\mathrm{A}$ is as low as 20.18 $\mathrm{mN} / \mathrm{m}$, and the surface tension of $3 \% \mathrm{ZPJ}-\mathrm{A}$ is only 0.03 $\mathrm{mN} / \mathrm{m}$ lower than that of the $2 \% \mathrm{ZPJ}-\mathrm{A}$, so considering its performance and economy, $2 \%$ of $\mathrm{ZPJ}-\mathrm{A}$ is preferred as the cleanup additive.

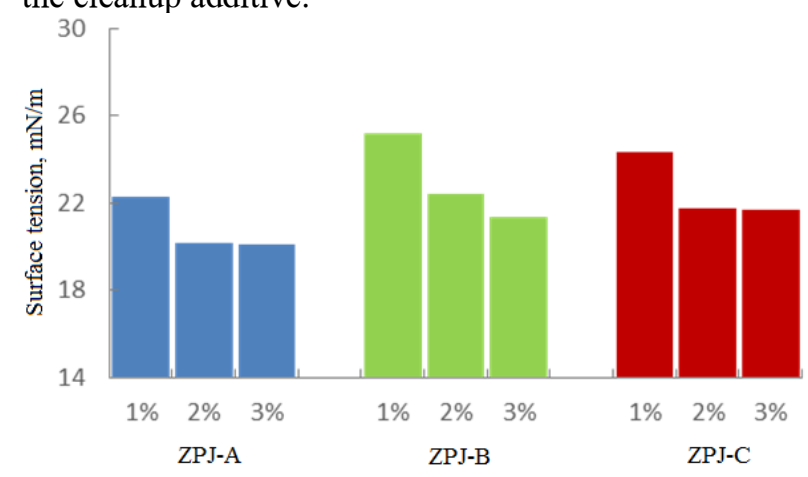

Fig.2. Surface tension test $3.4 \mathrm{~s}$

\subsection{Clay Stabilizer}

The clay stabilizer evaluation test was carried out on the composite acid with different anti-swelling agents ${ }^{[14]}$. The results are shown in Table 2 . PFJ-A has the highest anti-expansion rate, and FPJ-A is preferred as an anti-swelling agent.

Table 2. Clay stabilizer performance tests

\begin{tabular}{cc}
\hline Clay stabilizer & Anti-swell rate, $\%$ \\
\hline FPJ-A & $86.1 \%$ \\
FPJ-B & $81.3 \%$ \\
FPJ-C & $76.8 \%$ \\
\hline
\end{tabular}

\subsection{Scale Inhibitor}

The chelation ability of composite acid, EDTA, scale inhibitor and iron ion stabilizer for metal ions of calcium, magnesium and iron was tested. The test results are shown in Table 3. It can be seen that the composite acid has a strong ability to chelate metal ions, and it is not necessary to add any scale inhibitor and iron ion stabilizer in the acid solution, which reduces the acid cost. 
Table 3. Chelation ability comparison

\begin{tabular}{cccc}
\hline Agent & $\mathrm{Ca}^{2+}, \mathrm{mg} / \mathrm{g}$ & $\mathrm{Mg}^{2+}, \mathrm{mg} / \mathrm{g}$ & $\mathrm{Fe}^{3+}, \mathrm{mg} / \mathrm{g}$ \\
\hline Composite & 327.5 & 145.4 & 427.4 \\
acid & 115 & 131.8 & 150.2 \\
EDTA & 75.9 & 81.5 & - \\
Scale inbihitor & - & - & 93.1 \\
Iron ion & - & & \\
stabilizer & &
\end{tabular}

\section{Performance Evaluation of Acid System}

A novel composite acid formulation is formed: $3 \% \mathrm{HF}+$ $10 \% \mathrm{AH}+1 \% \mathrm{HSJ}-\mathrm{C}+2 \% \mathrm{ZPJ}-\mathrm{A}+2 \%$ FPJ-A. The performance of the acid system was evaluated by laboratory experiments.

\subsection{Evaluation of Acidity Characteristics}

The acidity characteristics of $10 \%$ of the new composite acid, $10 \%$ multi-hydrogen acid and mud acid were compared and tested, as shown in Figure 3. The initial $\mathrm{pH}$ value of the mud acid is $\operatorname{low}(2.33)$, the buffer performance is poor; the initial $\mathrm{pH}$ value of the multi-hydrogen acid is middle (2.83), which is higher than that of the mud acid, and the buffer property is better than the mud acid; the initial $\mathrm{pH}$ of the new composite acid is the highest value (3.51) and the ability to ionize hydrogen

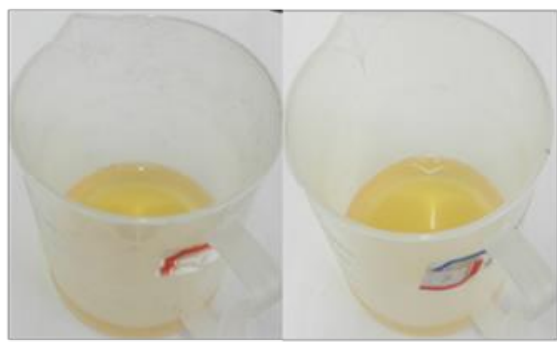

Block I

Block II ions in multiple steps. Therefore, in the acid-rock reaction, the initial reaction rate of the acid to rock minerals is low, and the hydrogen ions are slowly ionized, which has the potential to penetrate deep formation.

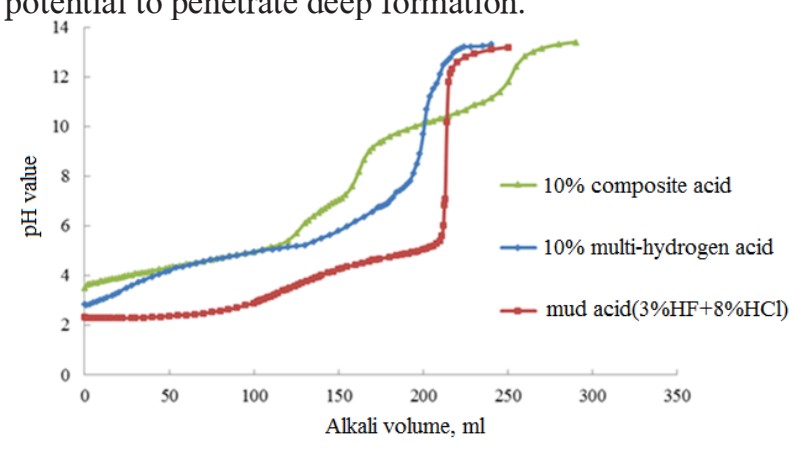

Fig.3. Evaluation of acidity characteristics.

\subsection{Evaluation of Compatibility}

The compatibility of the new composite acid with the formation water in different blocks was evaluated. The acid solution was separately heated and mixed with different blocks of formation water and additives at $95^{\circ} \mathrm{C}$ for 6 hours, and standing at indoor temperature for 48 hours. The solution was clear and transparent. The experimental results are shown in Figure 4. The compatibility of the new composite acid with the formation water is very good.

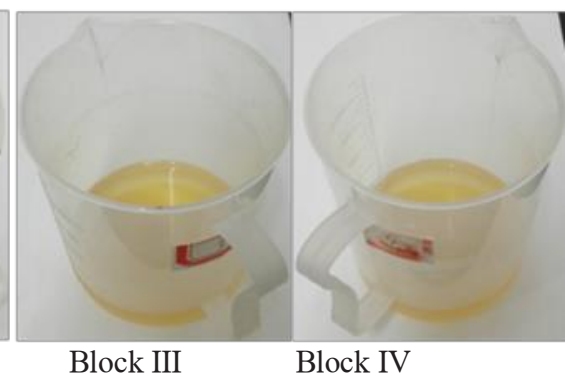

Fig.4. Evaluation of compatibility.

\subsection{Corrosion Inhibition Evaluation}

At the temperature $120^{\circ} \mathrm{C}$, pressure $6 \mathrm{MPa}$, four groups of N80 steel corrosion experiments were carried out. The measured corrosion rates of N80 steel were: 4.58, 4.96, 5.12 and $4.85 \mathrm{~g} / \mathrm{m}^{2} \cdot \mathrm{h}$ respectively. The average corrosion rate is $4.88 \mathrm{~g} / \mathrm{m}^{2} \cdot \mathrm{h}$, less than the primary industrial criterion of corrosion inhibitor $\left(10-20 \mathrm{~g} / \mathrm{m}^{2} \cdot \mathrm{h}\right)$.
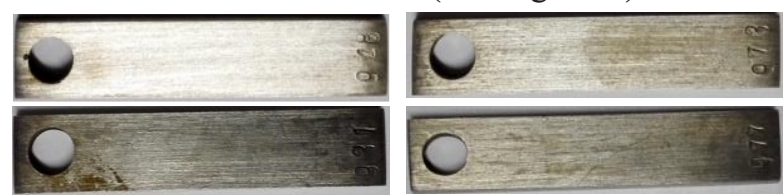

Fig.5. Evaluation of corrosion inhibition.

\subsection{Core displacement Experiment}

The core displacement experiment was carried out as shown in Fig. 6. It shows that in the new composite acid flooding process, the core permeability is slowly increased in three stages, and finally the core permeability is increased by 3.5 times. It shows that the new composite acid has good retardation and strong acid dissolution. It can meet the needs of deep penetrating acidified reservoirs.

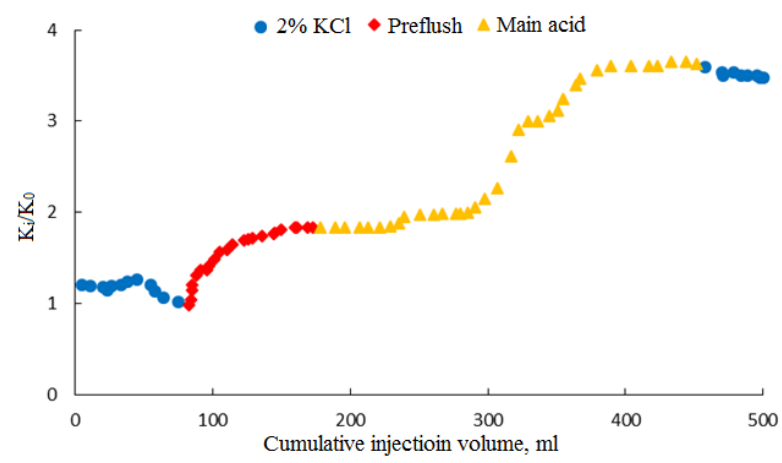

Fig.6. Core displacement Experiment. 


\section{Field Application}

At present, the new composite acid has been applied in 17 injection wells in 4 blocks of Huabei Oilfield. The average water injection pressure is reduced by $5.6 \mathrm{MPa}$, and the average daily water injection rate is increased by $16.3 \mathrm{~m}^{3}$.

Taking the XL-A well as an example, the geological parameters are shown in Table 4. The well has been acidized two times. The first conventional acid system was used. Before the treatment, the well can't be injected, and the average tubing pressure was $28.2 \mathrm{MPa}$. The effect after treatment is shown in Figure 7. The pressure is 26.1 $\mathrm{MPa}$ on average, which is $1.9 \mathrm{MPa}$ lower than before. The injection rate can meet the injection allocation at the beginning of post-treatment, and then decreased rapidly, and the final daily injection rate was $12 \mathrm{~m}^{3} / \mathrm{d}$.

Table 4. Chelation ability comparison

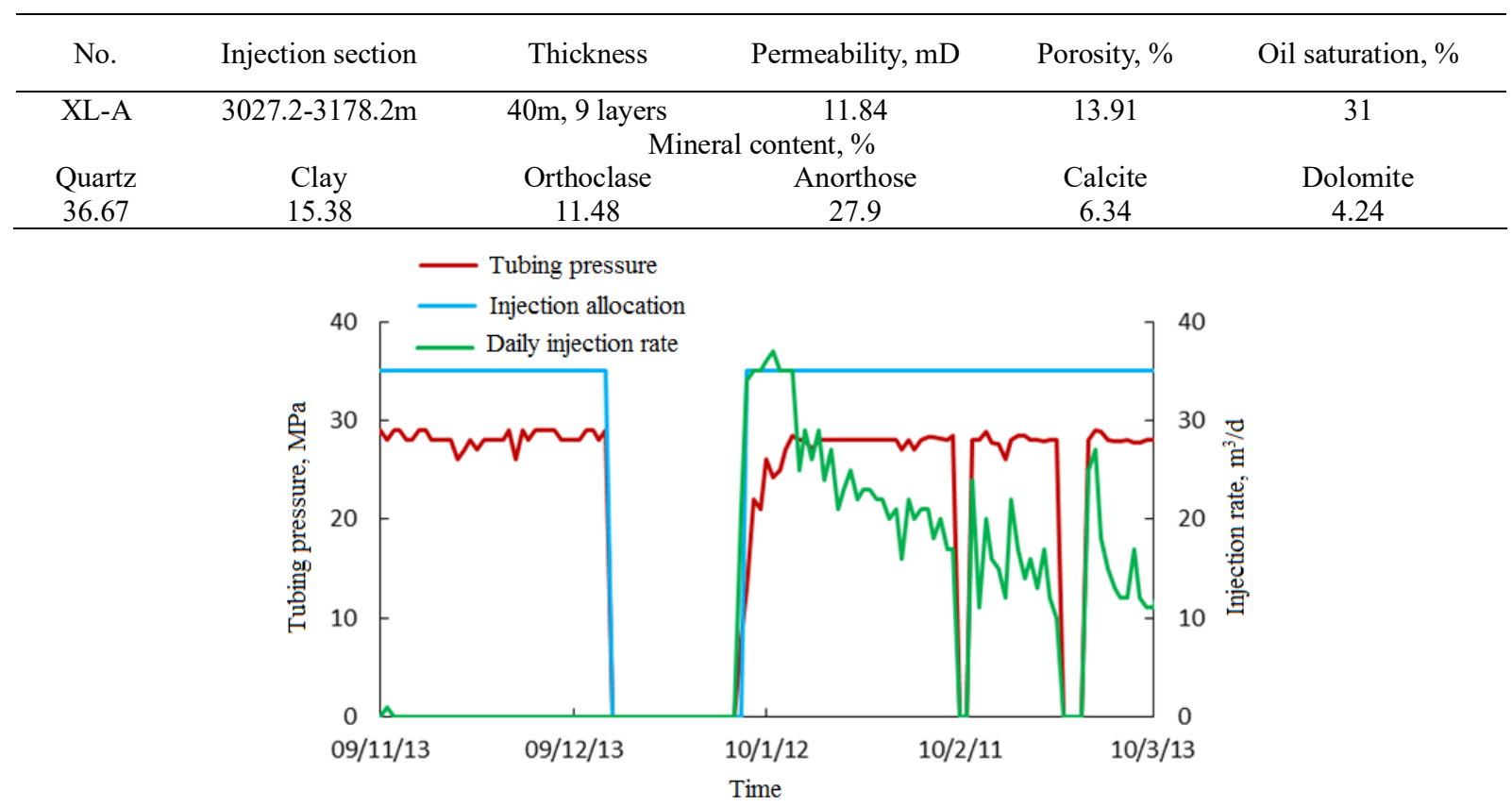

Fig.7. Acidizing effect of XL-A well used conventional acid.

At the second time, a new composite acid system was used. Before the treatment, the average injection pressure of the well was $32 \mathrm{MPa}$, and the average daily water injection was $4.3 \mathrm{~m}^{3} / \mathrm{d}$. The acidizing effect is shown in
Fig. 8. After the treatment, the water injection rate reaches the requirement of injection allocation. The injection pressure is $26 \mathrm{MPa}$ and remains stable.

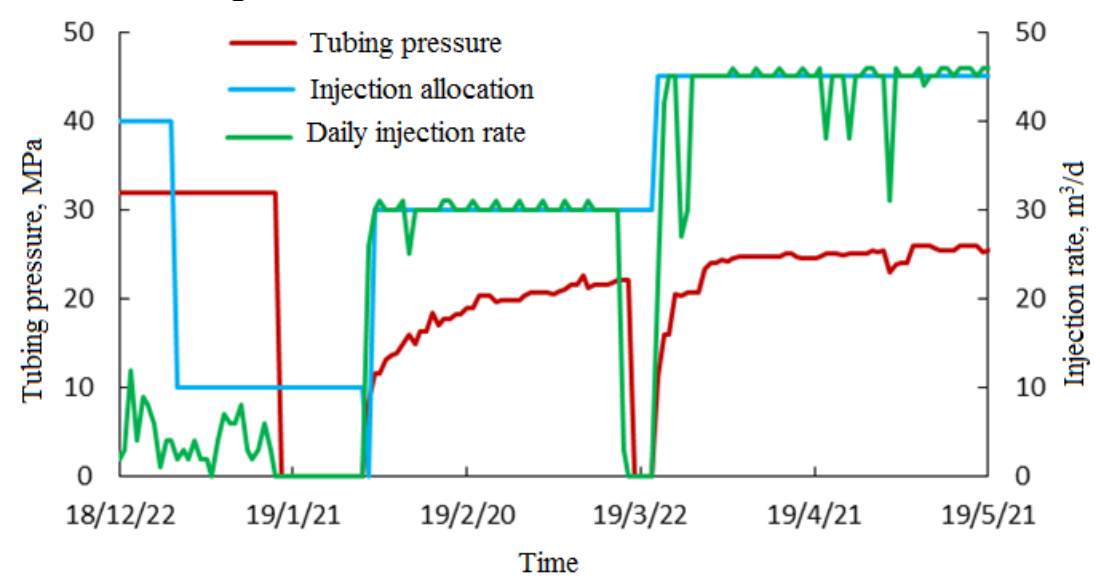

Fig.8. Acidizing effect of XL-A well used composite acid.

Comparison between the two acidizing effects shows that the conventional acid acidification distance is short, mainly in the vicinity of the wellbore. If the pollution zone cannot be effectively penetrated, the effect of acidizing and injection is limited, and the effective period of the treatment is very short. The new composite acid system has a long penetration distance, which can break through the pollution zone and stimulate the far-reaching stratum, which is beneficial to improve the effect of acidizing and increase the injection efficiency and prolong the effective period of the treatment. 


\section{Conclusion}

(1) The molecular structure of the novel composite acid main agent is identified by NMR. The AH molecule belongs to the aminocarboxylic acid chelate compound, which has 4 steps of $\mathrm{H}+$ ionization and contains a variety of carboxyl groups. It is a mechanism of slow retardation and chelation of the novel composite acid system.

(2) The performance evaluation of the new composite acid system is mainly carried out in terms of retardation, compatibility, corrosion inhibition and core displacement. The experiment results show that the system has the potential to stimulate far-reaching formation, and has good compatibility with formation water and additives. The average corrosion rate is $4.88 \mathrm{~g} / \mathrm{m}^{2} . \mathrm{h}$, which is less than the industrial criterion of corrosion inhibitor (10-20 $\left.\mathrm{g} / \mathrm{m}^{2} . \mathrm{h}\right)$. The increase of core permeability after the acidizing is greater than 3.5 times, indicating that the new composite acid system has a better acidizing effect on the actual reservoirs in Huabei Oilfield.

(3) The new composite acid system is a system suitable for low-permeability low-porosity and high-temperature sandstone reservoirs. It has the ability of retardance, scale inhibition, chelation, deep penetration and low damage

\section{Acknowledgments}

The project is supported by Huabei oilfield scienticfic research project (No. 2019-HB-C10). We would like to thank the staff of engineering technology research institute of Huabei oilfield.

\section{References}

1. Wu Anlin, Shen Liang, Wang Chuan. Development Status and Prospect of Acidizing Fluid System for Sandstone Matrix Acidification[J]. Journal of Chongqing University of Science and Technology (Natural Sciences Edition),2011,13(1): 95-97.

2. Liu Pingli, Lan Xitang, Wang Tianhui, et al. Development and research of a novel chelating acid system for sandstone reservoir acidification[J]. Natural Gas Industry,2014,34(4):72-75.

3. Ottar B. Acidification of Precipitation[C]. Norway: Acs Symposium, 2009.

4. Shi Zhiying, Wang Xinying, Gui Qinmin. Reserch and application of low-damage acid system[J]. Oil Drilling \& Production Technology,1991,13(4):75-78.

5. Yang F, Harbi B A. Acidizing Sandstone Reservoirs Using HF and Organic Acids[R].SPE 157250, 2012.

6. Zhu Hongwang. The key technologies of plug removal and injection stimulation in injection wells of Shanshan Oilfield Fractured Reservoir[D].Chengdu: Southwest Petroleum University, 2013.

7. Zhai Qia, Zhu Yali, Yu Yuehai, et al. Application of a new organic low damage composite acid in
Shuanghe oilfield V-IV oil group[J]. Petroleum Geology and Engineering, 2006,20(6):91-92.

8. Pei Tiemin,Wang Fangyi, WEI Hong, et al. Reserch and application of complex acid for plugging removal and injection stimulation technology in Weigang oilfield[J]. Journal of Oil and Gas Technology,2012,34(9):285-287.

9. Yuan Xuefang, Feng Jueyong, LI Yong, et al. New low chlorine chelating acid system and performance evaluation[J]. Journal of Oil and Gas Technology,2013,35(12):148-152.

10. Ekatatnyl S, Nasr-El-Din H A. Removal efficiency of water-based drill-in fluid filter cake using polylactic acid[R]. SPE 154192, 2012.

11. De Wolf C, Nasr-El-Din H A, Bouwman A, Bang E, Naylor E. A new low corrosive fluid to stimulate deep wells completed with Cr-based alloys[R]. SPE 152716, 2012.

12. Sokhanvarian K, Nasr-El-Din H A, Wang G, De Wolf C. Thermal stability of various chelates that are used in the oilfield and potential damage due to their decomposition product[R]. SPE 157426, 2012.

13. SY/T 5405-1996 Performance test method and evaluation index of corrosion inhibitor spree for acidification [S].

14. SY/T 5971-94 Performance evaluation method of clay stabilizer for water injection [S]. 